\title{
Is there a role for melatonin in the ICU?
}

\author{
G A Richards, ${ }^{1}$ MB BCh, PhD, FCP (SA), FRCP, MASSAf; OrcID 0000-0002-8893-3934; \\ A Bentley, ${ }^{2} \mathrm{MB}$ BCh, PhD; OrcID 0000-0001-6533-5213; \\ P D Gopalan, ${ }^{3} \mathrm{MB}$ ChB, PhD, FCA (SA), Crit Care (SA); OrcID 0000-0002-3816-1171; \\ L Brannigan, ${ }^{4} \mathrm{MB}$ BCh, DA (SA), FCA (SA), Cert Crit Care (SA); OrcID 0000-0002-6215-254; \\ F Paruk, ${ }^{5}$ MB BCh, PhD, FCOG (SA), Cert Crit Care (SA); OrcID 0000-0002-6259-0106 \\ ${ }^{1}$ Department of Critical Care, Faculty of Health Sciences, University of the Witwatersrand, Johannesburg, South Africa \\ ${ }^{2}$ Department of Family Medicine, Faculty of Heath Sciences, University of the Witwatersrand, Johannesburg, South Africa \\ ${ }^{3}$ Discipline of Anaesthesiology and Critical Care, School of Clinical Medicine, University of KwaZulu-Natal, Durban, South Africa \\ ${ }^{4}$ Department of Critical Care, WITS Donald Gordon Medical Centre, University of the Witwatersrand, Johannesburg, South Africa \\ ${ }^{5}$ Department of Critical Care, Faculty of Health Sciences, Steve Biko Academic Hospital, University of Pretoria, South Africa
}

Corresponding author: G A Richards (guy.richards@wits.ac.za)

In the last decade, there have been significant developments in the understanding of the hormone melatonin in terms of its physiology, regulatory role and potential utility in various domains of clinical medicine. Melatonin's purported properties include, among others, regulation of mitochondrial function, anti-inflammatory, anti-oxidative and neuro-protective effects, sleep promotion and immune enhancement. As such, its role has been explored specifically in the critical care setting in terms of many of these properties. This review addresses the physiological basis for considering melatonin in the critical care setting as well as the current evidence pertaining to its potential utility.

Keywords. melatonin; sleep; delirium; sepsis; intensive care unit.

South Afr J Crit Care 2021:37(1):77-82. https://doi.org/10.7196/SAJCC.2021.v37i2.490

Contributions of the study. This review examines and discusses the role of melatonin in the intensive care unit in terms of sleep, delirium and sepsis, both the physiology and as a therapy.

Melatonin is a hormone that is secreted primarily by the pineal gland but is also synthesised in the gastrointestinal tract, the retina and in polymorphonuclear leukocytes. ${ }^{[1]}$ It is derived from tryptophan metabolism via hydroxytryptophan, serotonin and $\mathrm{N}$-acetyl serotonin with secretion from the pineal maximal at night, regulating circadian rhythms and sleep initiation. ${ }^{[2,3]}$ Melatonin is also produced in extra pineal sites but these do not follow a circadian cycle except for the retina, where it functions as an antioxidant. ${ }^{[4]}$ The hormone influences mitochondrial metabolism and displays anti-inflammatory and antioxidative effects. In addition, it also increases the expression of other antioxidants such as glutathione, and stimulates activation of enzymes such as glutathione peroxidase, superoxide dismutase, catalase and glutathione reductase. ${ }^{[5-7]}$

Several inflammatory cells harbour melatonin receptors, including T-lymphocytes, natural killer cells, eosinophils and mast cells. In these cells, melatonin inhibits translocation of nuclear factor-kappa B (NF-kB) to the nucleus, moderating production of pro-inflammatory

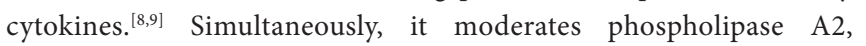
lipoxygenase and cyclooxygenase activity influencing production of the products of arachidonic acid metabolism, ${ }^{[10]}$ and reduces inflammation and the activation of nod-like receptor protein-3 inflammasome induced by lipopolysaccharide. ${ }^{[11-13]}$

There is considerable literature from animal studies describing potential neuroprotective effects, such as modulation of excitatory responses following trauma or other insults by attenuation of n-methyl-
$D$-aspartic acid receptor activity. ${ }^{[14]}$ Numerous other effects have been demonstrated in vivo such as promotion of axonal regrowth, protection of the myelin sheath and nerve maturation. ${ }^{[15,16]}$

The aforementioned effects suggest that melatonin may play a role in the intensive care unit (ICU) to promote sleep, reduce delirium and to modulate the inflammatory response in sepsis.

\section{Melatonin, sleep and the ICU}

Melatonin is produced in the pineal gland when light fades in the evening, creating a surge described as the dim-light melatonin onset phenomenon. As the hormone levels rise, there is an associated drop in body temperature with an increase in sleep propensity (Fig. 1). Body temperature remains low throughout the night commensurate with the high melatonin level but as levels drop, the temperature rises, creating a natural wake time.

During the day, the action of light on the retina suppresses production of melatonin (sunlight usually provides between 30000 and 60000 lux), which is a strong stimulus to switch off production. ${ }^{[17]}$ The significant decrease in light that occurs in the evening again drives melatonin production, promoting the 24-hour circadian rhythm. The presence of excess artificial light at night in environments such as the ICU can disrupt the nocturnal melatonin secretion.

The drop in body temperature is caused by the action of melatonin on the suprachiasmatic nucleus (SCN) in the hypothalamus - the so-called central circadian timekeeper. There are also tissue specific peripheral clocks in all cells including immune cells such as macrophages, which 


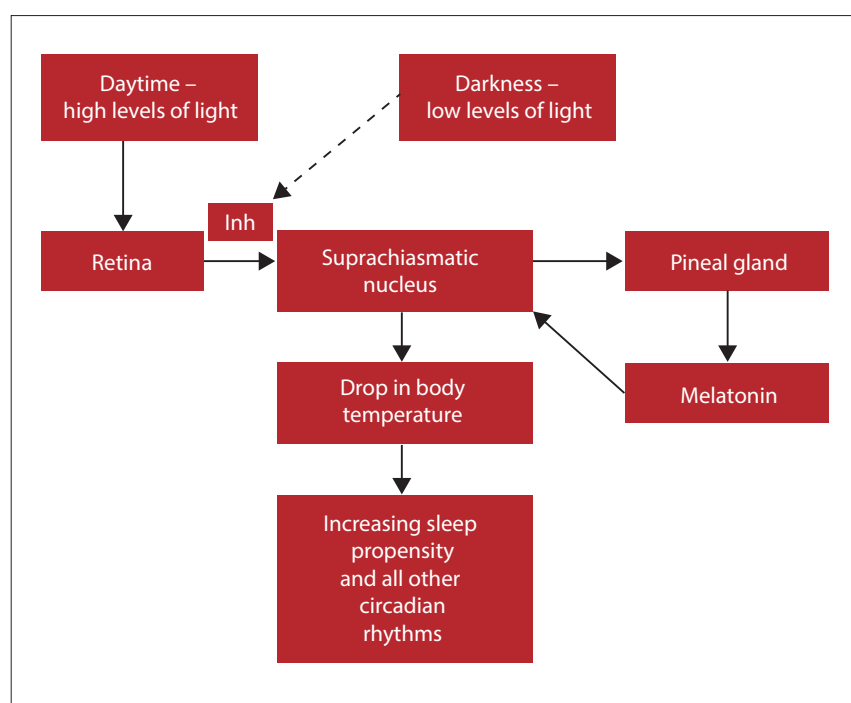

Fig. 1. Action of light on the release of melatonin from the pineal gland. Dotted lines indicate release of inhibition of daytime light effect by darkness. $($ Inh = inhibition .

are controlled by the SCN by influencing the timing of feeding and activity as well as regulating the rhythmic release of hormones. ${ }^{[18]}$

Ideally, both the central and peripheral clocks should be aligned and environmental factors should synchronise these internal clocks with the external environment. These clocks may be disconnected in some circumstances such as with sepsis ${ }^{[17]}$ and with changes in the external environment, such as flight over time zones or the disruptive ICU environment, which can temporarily desynchronise internal clocks from the external environment.

Temperature and sleep rhythms do not occur in isolation. Many other bodily functions have circadian rhythms, such as the well-known dip in blood pressure and decrease in gut motility that occur at night. Recognition of the importance of these circadian clocks with regard to the best time for delivery of medications has created a field of medicine known as chronotherapy, where drugs are given at the correct circadian time to effect the best possible response and lowest toxicity. ${ }^{[19]}$ This may also have relevance to continuous v. daytime feeding in the ICU. ${ }^{[20]}$

There are many disruptors of circadian rhythms and sleep (i.e. continuous light, noise, medications, feeding times and frequent patient-care interactions) in the ICU. ${ }^{[18]}$ While light levels are usually relatively low (between 30 and 165 lux during the day and 2.4 to 145 lux at night), it is the lack of a significant change in light intensity during the 24-hour period that compromises the circadian rhythm. In addition, light devices that are used for procedures in the ICU may emit up to 10000 lux, which in the low light environment of the ICU may be enough to alter circadian rhythms. ${ }^{[17]}$ As a consequence, the timing of a drop in body temperature may shift, occurring at any time during a 24-hour period in an ICU patient. ${ }^{[18]}$ Healthy people subjected to a simulated ICU environment had decreased melatonin levels, total sleep time, quantity of rapid eye movement (REM) sleep and sleep quality, while sleep onset latency increased. ${ }^{[21]}$ Total sleep time in the ICU may remain the same but the distribution of sleep may be significantly altered, with severe fragmentation occurring throughout the 24-hour period and up to $57 \%$ of sleep occurring during the day. ${ }^{[17]}$ The differences between a disrupted circadian rhythm in an ICU environment and the normal rhythm are diagrammatically represented in Figs $2 \mathrm{~A}$ and B. ${ }^{[22]}$

Changes in circadian rhythm are particularly problematic in elderly patients in the ICU. Elderly patients have reduced sleep time and sleep is more fragmented with an increased number of nocturnal awakenings. This is associated with loss of slow-wave sleep while REM sleep is maintained. ${ }^{[23]}$ Part of the reason for the worse sleep quality in the elderly may be due to a lowered melatonin level, which gradually declines from childhood to a level below useful by the age of 60 years. ${ }^{[24]}$ Thus, circadian rhythms and sleep periods become less adaptable and linked more to social cues (time and activity based) than to melatonin. In line with this, sleep quality in the elderly outside of the ICU situation can be significantly improved by replacement of melatonin without the side-effects usually associated with typical hypnotics. ${ }^{[25]}$

Disturbance in circadian rhythm and melatonin homeostasis have been implicated in the development of ICU delirium, which presents with waxing and waning levels of consciousness associated with periods of inattention and confusion. ${ }^{[26]}$ Delirium occurs in up to $70 \%$ of adults in ICU and is associated with an increased length of hospital stay, longterm cognitive impairment and in some cases early death. There are many risk factors that contribute to its development, including among others advanced age and medical comorbidities, which do not lend themselves to modification. However, there are also several modifiable risk factors such as the control of pain and sleep, and avoidance of sedative agents such as the benzodiazepines. ${ }^{[2]}$ The relationship between delirium and circadian sleep cycle disruption is well described and likely bidirectional. Thus, increased daytime sleep, fragmentation of sleep and poor sleep quality increase the risk of delirium, and the presence of delirium in turn negatively impacts attempts to sleep. ${ }^{[22,28]}$ Sleep disruption and delirium are particularly prevalent $(80 \%)$ in patients receiving mechanical ventilation. ${ }^{[29]}$

ICU clinicians (97\%) believe that poor sleep is a risk factor for delirium. ${ }^{[28]}$ Evidence for this is that patients with sleep-disordered breathing who have a poor sleep quality have a 6 -fold increase in the risk of delirium postoperatively. ${ }^{[30]}$ Mechanical ventilation causes 18 - 35 arousals per hour, which would be equivalent to a diagnosis of moderate to severe obstructive sleep apneoa. ${ }^{[28]}$ In addition, certain interventions can improve sleep quality and reduce delirium..$^{[28,30,31]}$

Several trials have shown the effectiveness of earplugs and eyeshields in increasing the contrast between 'day' and 'night' to protect both circadian rhythms and sleep. ${ }^{[21]}$ Specifically timed bright light therapy has been used for many circadian disorders but has not been found to be effective in the ICU environment. ${ }^{[28]}$ Certain complementary therapies such as acupressure, aroma and music therapy also appear to be promising but have not been validated for widespread use. ${ }^{[33]}$ A critical review of the evidence for non-pharmacological and pharmacological interventions comprising 41 studies showed that multiple interventions do appear to improve sleep; however, there is a lack of high-quality intervention studies. ${ }^{[32]}$

Exogenous melatonin has been shown to impove sleep quality more than earplugs and eyeshields in healthy volunteers in a simulated ICU environment. ${ }^{[21]}$ It also improved sleep quality and daytime alertness in patients over the age of 55 years outside of the ICU environment with poor sleep quality, with very few side-effects. The 2018 critical care guidelines, however, reviewed three randomised controlled trials (RCTs) and found no support for the use of exogenous melatonin. ${ }^{[25,28]}$ Since then, however, more trials have been published and the most recent meta-analysis of nine RCTs using exogenous melatonin, despite a significant heterogeneity in the studies, found a significant decrease in the risk of delirium (risk ratio 0.51; 95\% confidence interval $0.30-0.85 ; p=0.01)$ ). ${ }^{[34]}$ There was no overall change in length of stay in ICU in this meta-analysis but reduction in delirium is in itself a positive outcome given the long-term consequences including 
A

\begin{tabular}{|l|l|}
\hline $6 \mathrm{am}$ & \multicolumn{2}{l|}{$6 \mathrm{pm}$} \\
\hline Lighter, noisier, warmer & Darker, quieter, cooler \\
\hline \multicolumn{2}{|l|}{$6 \mathrm{pleep}$} \\
\hline Awake & \\
\hline & \\
\hline
\end{tabular}

B

\begin{tabular}{|l|l|l|l|l|}
\hline $6 \mathrm{am}$ & & $6 \mathrm{pm}$ & & $6 \mathrm{am}$ \\
\hline & & & & \\
\hline
\end{tabular}

Lighter, noisier, warmer - constantly

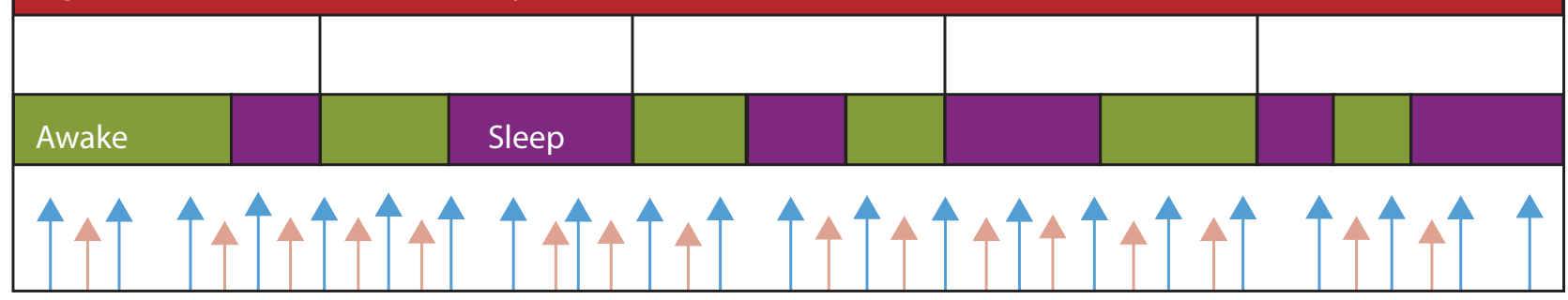

Fig. 2. Normal day and night (A) and changes in light, sleep and hormones in an ICU environment (B). Blue arrows indicate cortisol secretion and brown arrows indicate that of melatonin. Adapted from Daou et al. ${ }^{[22]}$

prolonged institutionalisation, higher hospital costs, longer duration of ventilation, and in some studies higher mortality rate. ${ }^{[26]}$ There have also been a few studies of ramelteon as a melatonin agonist on reduction of delirium in the ICU. In one small RCT of 88 patients, there was a trend toward a decrease in length of ICU stay but there was a significant decrease in the incidence and duration of delirium in the group that received ramelteon. ${ }^{[35]}$

Use of multicomponent strategies appears to be the most useful means to improve sleep quality in the ICU and to reduce the risk of delirium. The combination of dexmedetomidine, oral melatonin and cognitive behavioural therapy to adjust sleep timing and behaviours has been suggested. ${ }^{[22]}$ Adjustment of feeding times, light intensity (to create a contrast between day and night), and interactions with patients by healthcare workers are all necessary components of any intervention to improve sleep quality. This multi-component approach should include more deliberate assessments of pain and sedation, and involvement of the family where possible, as in the ABCDEF bundle, which has shown reduction in delirium, ventilator days and ICU readmissions. Of interest, the bundle does not include any specific sleep recommendations other than a suggestion to implement sleep hygiene measures under the section on prevention of delirium. ${ }^{[36]}$ However, many of the specific recommendations that are included, such as pain management and a reduction in pharmacological sedation, would also improve sleep quality. Currently, there are no studies that use a combination of the ABCDEF bundle and melatonin, but this is a fertile area for further investigation.
The evidence for the importance of circadian rhythms and sleep in the ICU patient is well recognised. The impact of poor sleep, particularly in elderly patients in the ICU on the risk of delirium, has been accepted by the Society of Critical Care Medicine along with necessary interventions such as the ABCDEF bundle. ${ }^{[28]}$ However, the evidence for the use of melatonin and other environmental strategies to improve sleep quality, and in so doing reduce the risk of delirium, is currently insufficient. Given the positive signal from emerging RCTs and the meta-analyses regarding the benefit of melatonin, and its good safety profile, it should be considered as an option to improve sleep quality in the ICU. Further research will more clearly define the role and use of melatonin in this situation.

\section{Sepsis and melatonin}

Depending on the severity of the disease, the host response to sepsis may comprise an exaggerated pro-inflammatory response, associated with oxidative imbalance and mitochondrial dysfunction. Melatonin has been observed to exhibit potent anti-inflammatory, anti-apoptotic, antioxidant and antibacterial properties, which render it an attractive candidate as an adjuvant therapy in sepsis from an immunomodulatory and a metabolic resuscitation perspective. ${ }^{[37,38]}$ Table 1 indicates the data obtained from animal studies, as there are very few human studies.

Virally mediated sepsis has also been an area of investigation almost entirely in animal studies. ${ }^{[58]}$ Melatonin is not viricidal but the indirect actions described in Table 1, i.e. the anti-inflammatory and anti- 
Table 1. The role of melatonin in sepsis in animal studies

\section{Role}

Antioxidant

Restoration of glutathione

levels

Anti-inflammatory

\section{Mitochondrial protection} Organ protection (hepatic, cardiac and neurological)

Antibacterial effect

\section{Mechanism}

ROS scavenger ${ }^{[39-41]}$

Stimulation of synthesis of antioxidant enzymes $^{[42-44]}$

Reduces pro-inflammatory cytokines and increases anti-inflammatory cytokines $^{[45-49]}$

Inhibition of overexpression of iNOS ${ }^{[00-54]}$

Reduced NO levels ${ }^{[46,55-57]}$

Promotion of NET formation, which kill bacteria in sepsis ${ }^{[37,41]}$

ROS $=$ reactive oxidant species; $\mathrm{iNOS}=$ inducible nitric oxide synthase; $\mathrm{NO}=$ nitric oxide; $\mathrm{NET}=$ neutrophil extracellular trap.

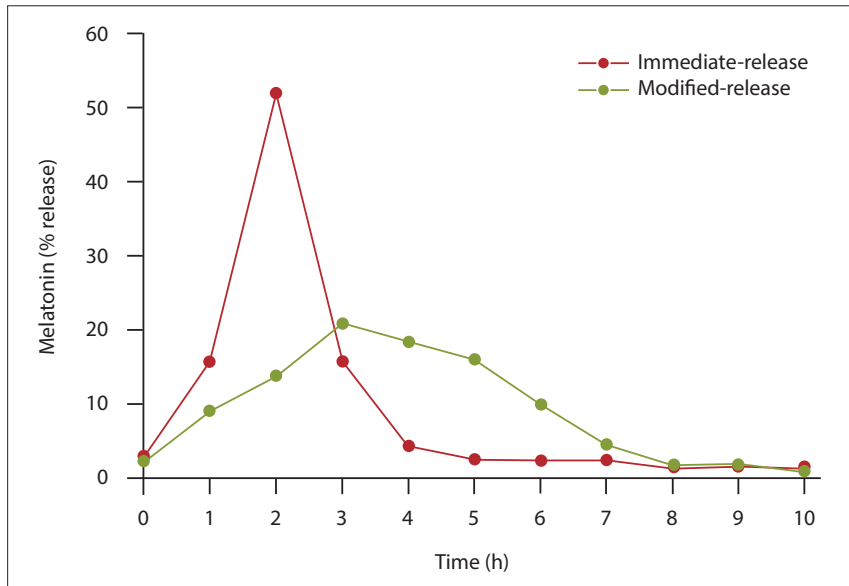

Fig. 3. Pharmacokinetic profile of PRM (Circadin) compared with FR-melatonin $2 \mathrm{mg}$ formulation. Adapted from Zisapel. ${ }^{[64]}$

oxidative effects and immune enhancement make it a potential but unproven therapy for viruses. Pre-treatment of animals with melatonin resulted in a marked reduction of acute lung oxidative injury in a model of infection with respiratory syncytial virus (RSV), with suppression of nitric oxide, hydroxyl radical and malondialdehyde generation. ${ }^{[59]}$ It restored glutathione and superoxide dismutase levels in the lung and reduced pro-inflammatory cytokines such as tumour necrosis factoralpha (TNF- $\alpha){ }^{[59]}$ In addition, it decreased toll-like receptor-mediated downstream gene expression in RSV-infected macrophages, and NF-kBdependent gene expression such as those encoding for TNF- $\alpha$ and inducible nitric oxide synthase. ${ }^{[60,61]}$

Although there are no human studies showing clear benefit, melatonin has been pre-emptively included as a potential therapy in some clinical protocols for the management of viral infections. ${ }^{[2]}$ Notably, most sources recommend doses far higher than those used for sleep, with some indicating that benefit would only be achieved with dose ranges between $40 \mathrm{mg}$ and as high as $500 \mathrm{mg}$, which would be extremely difficult to achieve and have potential for as yet unrecognised toxicity. ${ }^{[63]}$ Formulations of melatonin come in two types: fast- or a prolongedrelease format. Fast-release melatonin reaches a peak within 2 hours and decreases just as quickly, while the prolonged-release formulation has a slow onset but remains active for up to 6 or 7 hours. ${ }^{[64]}$ The pharmacokinetics of the prolonged-release format best represents the physiological secretion of melatonin with the peak level half that of the fast-release formulation (Fig. 3). All published studies mention the dose that was utilised but many do not define which formulation was used

or the time that it was administered. It is difficult to make comparisons of the available literature because doses vary and there is a lack of clarity as to the formulation or the timing of administration.

Melatonin's potential utility in sepsis is appealing; however, it is mainly informed by studies in animal models and more studies in humans are required. In the context of sepsis, key considerations include the demonstration of outcome benefit, determination of optimal dose and timing as well as duration and route of administration (oral route has a bioavailability of $3-33 \%$ ) and the impact of its use in adults. ${ }^{2}$

Melatonin's potential role in the ICU to promote sleep, decrease delirium and to modulate the inflammatory response in sepsis remains promising, but needs further well-constructed studies to definitive conclusions.

\section{Declaration. None.}

\section{Acknowledgements. None.}

Author contributions. All authors wrote the manuscript. All authors approved the final version of the manuscript for publication.

Funding. None.

Conflicts of interest. None.

1. Claustrat B, Brun J, Chazot G. The basic physiology and pathophysiology of melatonin. Sleep Med Rev 2005:9:11-24. https://doi.org/10.1016/j.smrv.2004.08.001

2. Pandi-Perumal SR, Srinivasan V, Maestroni GJM, Cardeneli DP, Poeggeler B, Hardeland R Melatonin: Natures most versatile biological signal? FEBS J 2006;273:2813-2838. https://doi. org/10.1111/j.1742-4658.2006.05322.x

3. Chattoraj A, Liu T, Zhang LS, Huang Z, Borjigin J. Melatonin formation in mammals: In vivo perspectives. Rev. Endocr Metab Disord 2009;10:237-243. https://oi.org/10.1007/s11154-0099125-5

4. Acuna-Castroviejo D, Escames G, Venegas C, et al. Extrapineal melatonin: Sources, regulation, and potential functions. Cell Mol Life Sci 2014;71;2997-3025. https://doi.org/10.1007/s00018014-1579-2

5. Tan DX, Manchester LC, Esteban-Zubero E, Zhou Z, Reiter RJ. Melatonin as a potent and inducible endogenous antioxidant: Synthesis and metabolism. Molecules 2015;20:18886-18906. https://doi.org/10.3390/molecules201018886

6. Leaw B, Nair S, Lim R, Thornton C, Mallard C, Hagberg H. Mitochondria, bioenergetics and excitotoxicity: New therapeutic targets in perinatal brain injury. Front Cell Neurosci 2017;11:199. https:doi.org/10.3389/fncel.2017.00199

7. Tomas-Zapico C, Coto-Montes A. A proposed mechanism to explain the stimulatory effect of melatonin on antioxidative enzymes. J Pineal Res 2005;39:99-104. https://doi.org/10.1111/j.1600 079X.2005.00248.x

8. Yu GM, Kubota H, Okita M, Maeda T. The anti-inflammatory and antioxidant effects of melatonin on LPS-stimulated bovine mammary epithelial cells. PLoS ONE 2017;12,e0178525. https://doi.org/10.1371/journal.pone.0178525

9. Garcia JA, Volt H, Venegas C, et al. Disruption of the NF-kappaB/NLRP3 connection by melatonin requires retinoid-related orphan receptor-alpha and blocks the septic response in mice. FASEB J 2015;29:3863-3875. https://doi.org/10.1096/fj.15-273656

10. Deng WG, Tang ST, Tseng HP, Wu KK. Melatonin suppresses macrophage cyclooxygenase-2 and inducible nitric oxide synthase expression by inhibiting $\mathrm{p} 52$ acetylation and binding. Blood 2006;108:518-524. https://doi.org/10.1182/blood-2005-09-3691

11. Liu Z, Gan L, Xu Y, et al. Melatonin alleviates inflammasome-induced pyroptosis through nhibiting NF-kappaB/GSDMD signal in mice adipose tissue. J. Pineal Res 2017;63:e12414. https://doi.org/10.1111/jpi.12414

12. Volt H, García JA, Doerrier C, Díaz-Casado ME, Guerra-Librero A, López LC. Same molecule but different expression: Aging and sepsis trigger NLRP3 inflammasome activation, a target of melatonin. J Pineal Res 2016;60:193-205. https://doi.org/10.1111/jpi.12303

13. Favero G, Franceschetti L, Bonomini F, Rodella LF, Rezzani R. Melatonin as an anti-inflammatory agent modulating inflammasome activation. Int J Endocrinol 2017;2017:1835195. https://doi org/10.1155/2017/1835195

14. Wang S, Tian Y, Song L, et al. Exacerbated mechanical hyperalgesia in rats with genetically predisposed depressive behavior: Role of melatonin and NMDA receptors. Pain 2012;153:24482457. https://doi.org/10.1016/j.pain.2012.08.016

15. Olivier P, Fontaine RH, Loron G, et al. Melatonin promotes oligodendroglial maturation of injured white matter in neonatal rats. PLoS ONE 2009;4:e7128. https://doi.org/10.1371/journal. pone. 0007128

16. Padilla-Gomes NF, Enríquez G, Acosta-Rojas R, et al. Prevalence of neonatal ultrasound brain lesions in premature infants with and without intrauterine growth restriction. Acta Paediat 2007;96:1582-1587. https://doi.org/10.1111/j.1651-2227.2007.00496.x

17. Telias I, Wilcox ME. Sleep and circadian rhythm in critical illness. Crit Care 2019:23:82. https://doi. org/10.1186/s13054-019-2366-0

18. Jobanputra AM, Scharf MT, Androulakis IP, Sunderram J. Circadian disruption in critical illness. Front Neurol 2020;11:820. https://doi.org/10.3389/fneur.2020.00820

19. Dong D, Yang D, Lin L, Wang S, Wu B. Circadian rhythm in pharmacokinetics and its relevance to chronotherapy. Biochem Pharmacol 2020;178:114045. https://doi.org/10.1016/j.bcp.2020.114045

20. Sunderram J, Sofou S, Kamisoglu K, Karantza V, Androulakis IP. Time-restricted feeding and the realignment of biological rhythms: Translational opportunities and challenges. I Transl Med 2014;12:79. https://doi.org/10.1186/1479-5876-12-79

21. Huang H, Zheng B-L, Jiang L, et al. Effect of oral melatonin and wearing earplugs and eye masks on nocturnal sleep in healthy subjects in a simulated intensive care unit environment: Which might be a more promising strategy for ICU sleep deprivation? Randomised Controlled Trial Crit Care 2015;19(1):124. https://doi.org/10.1186/s13054-015-0842-8 
22. Daou M, Telias I, Younes M, Brochard L, Wilcox E. Abnormal sleep, circadian rhythm disruption, and delirium in the ICU: Are they related? Front Neurol 2020;11:549908. https://doi.org/10.3389/ fneur.2020.549908

23. Ohayon MM, Carskadon MA, Guilleminault C, Vitiello MV. Meta-analysis of quantitative sleep parameters from childhood to old age in healthy individuals: Developing normative sleep values across the human lifespan. Sleep 2004;1;27(7):1255-1273. https://doi.org/10.1093/sleep/27.7.1255

24. Waldhauser F, Weiszenbacher G, Tatzer E, et al. Alterations in nocturnal serum melatonin levels in humans with growth and aging. J Clin Endocrinol Metab 1988;66(3):648-652. https://doi. org/10.1210/jcem-66-3-648

25. Wade A, Ford I, Crawford G, et al. Efficacy of prolonged release melatonin in insomnia patients aged 55 - 80 years: Quality of sleep and next-day alertness outcomes. Curr Med Res Opin 2007;23(10):2597-2605. https://doi.org/10.1185/030079907X233098

26. Farasat S, Dorsch J, Pearce A, et al. Sleep and delirium in older adults. Curr Sleep Med Rep 2020:113. https://doi.org/10.1007/s40675-020-00174y

27. Brummel NE, Girard TD. Preventing delirium in the intensive care unit. Crit Care Clin 2013;29:5165. https://doi.org/10.1016/j.ccc.2012.10.007

28. Devlin J, Skrobik Y, Gélinas C, et al. Clinical practice guidelines for the prevention and management of pain, agitation/sedation, delirium, immobility, and sleep disruption in adult patients in the ICU. Practice Guideline Crit Care Med 2018;46(9):e825-e873. https://doi.org/10.1097/ CCM.0000000000003299

29. Salluh JI, Wang H, Schneider EB, et al. Outcome of delirium in critically ill patients: Systematic review and meta-analysis. BMJ 2015;350:h2538. https://doi.org/10.1136/bmj.h2538

30. Kamdar BB, Knauert MP, Jones SF, et al. Perceptions and practices regarding sleep in the intensive care unit. A survey of 1223 critical care providers. Ann Am Thorac Soc 2016;13:1370-1377. https:// doi.org/10.1513/AnnalsATS.201601-087OC

31. Roggenbach J, Klamann M, von Haken R, Bruckner T, Karck M, Hofer S. Sleep-disordered breathing is a risk factor for delirium after cardiac surgery: A prospective cohort study. Crit Care 2014;18(5):477. https://doi.org/10.1186/s13054-014-0477-1

32. Cooke M, Ritmala-Castrén M, Dwan T, Mitchell M. Effectiveness of complementary and alternative medicine interventions for sleep quality in adult intensive care patients: A systematic review. Int J Nurs Stud 2020;107:103582 https://doi.org/10.1016/j.ijnurstu.2020.103582

33. Brito R, Viana S, Beltrão B, Magalhães C, de Bruin V, de Bruin P. Pharmacological and nonpharmacological interventions to promote sleep in intensive care units: A critical review. Sleep Breath 2020;24(1):25-35. https://doi.org/10.1007/s11325-019-01902-7

34. Zhu $\mathrm{Y}$, Jiang $\mathrm{Z}$, Huang $\mathrm{H}$, et al. Assessment of melatonergics in prevention of delirium: A systematic review and meta-analysis. Front Neurol 2020;11:198. https://doi.org/10.3389/fneur.2020.00198

35. Nishikimi N, Numaguchi A, Takahashi K, et al. Effect of administration of ramelteon, a melatonin receptor agonist, on the duration of stay in the ICU. Crit Care Med 2018;46(7):1099-1105. https:// doi.org/10.1097/CCM.0000000000003132

36. Marra A, Ely WE, Pandharipande PP, Patel MB. The ABCDEF bundle in critical care. Crit Care Clin 2017;33(2):225-243. https://doi.org/10.1016/..ccc.2016.12.005

37. Xu L, Zhang W, Kwak M, Zhang L, Lee PCW, Jin J. Protective effect of melatonin against polymicrobial sepsis is mediated by the anti-bacterial effect of neutrophils. Front Immunol 2019;10:1371. https://doi.org/10.3389/fimmu.2019.01371

38. Biancatelli RMLC, Berrill M, Mohammed YH, Marik PE. Melatonin for the treatment of sepsis: The scientific rationale. J Thorac Dis 2020;12(Suppl 1):S54-S65. https://doi.org/10.21037/jtd.2019.12.85

39. Jou MJ, Peng TI, Reiter RJ, Jou S-B, Wu H-Y, Wen S-T. Visualisation of the antioxidative effects of melatonin at the mitochondrial level during oxidative stress-induced apoptosis of rat brain astrocytes. J Pineal Res 2004;37(1):55-70. https://doi.org/10.1111/j.1600-079X.2004.00140.x

40. Galano A, Tan DX, Reiter RJ. On the free radical scavenging activities of melatonin's metabolites, AFMK and AMK. J Pineal Res 2013;54:245-257. https://doi.org/10.1111/jpi.12010

41. Wu JY, Tsou MY, Chen TH, Chen S-J, Tsao C-M, Wu CC. Therapeutic effects of melatonin on peritonitis-induced septic shock with multiple organ dysfunction syndrome in rats. J Pineal Res 2008;45(1):106-116. https://doi.org/10.1111/j.1600-079X.2008.00567.x

42. Sewerynek E, Abe M, Reiter RJ, et al. Melatonin administration prevents lipopolysaccharideinduced oxidative damage in phenobarbital-treated animals. J Cell Biochem 1995;58(4):436-444. https://doi.org/10.1002/jcb.240580406
43. Pandi-Perumal SR, Trakht I, Srinivasan V, et al. Physiological effects of melatonin: Role of melatonin receptors and signal transduction pathways. Prog Neurobiol 2008;85(3):335-353. https://doi. org/10.1016/j.pneurobio.2008.04.001

44. Reiter RJ. Interactions of the pineal hormone melatonin with oxygen-centered free radicals: A brief review. Braz J Med Biol Res 1993;26:1141-1155.

45. Sener G, Toklu H, Kapucu C, et al. Melatonin protects against oxidative organ injury in a rat model of sepsis. Surg Today 2005;35:52-59. https://doi.org/10.1007/s00595-004-2879-1

46. Zhang J, Wang L, Xie W, et al. Melatonin attenuates ER stress and mitochondrial damage in septic cardiomyopathy: A new mechanism involving BAP31 upregulation and MAPK-ERK pathway. J Cell Physiol 2020;235(3):2847-2856. https://doi.org/10.1002/jcp.29190

47. Li Z, Nickkholgh A, Yi X, Bruns $\mathrm{H}$, et al. Melatonin protects kidney grafts from ischemia/reperfusion injury through inhibition of NF-kB and apoptosis after experimental kidney transplantation. J injury through inhibition of NF-kB and apoptosis after experimental kidney
Pineal Res 2009;46(4):365-372. https://doi.org/10.1111/j.1600-079X.2009.00672.x

48. Shang Y, Xu S-P, Wu Y, et al. Melatonin reduces acute lung injury in endotoxemic rats. Chin Med (Engl) 2009;122(12):1388-1393.

49. Da Rosa DP, Forgiarini LF, e Silva MB, et al. Antioxidants inhibit the inflammatory and apoptotic processes in an intermittent hypoxia model of sleep apnea. Inflamm Res 2015;64: 21-29. https://doi.org/10.1007/s00011-014-0778-5

50. Kirkebøen KA, Strand OA. The role of nitric oxide in sepsis - an overview. Acta Anaesthesiol Scand 1999;43:275-288. https://doi.org/10.1034/j.1399-6576.1999.430307.x

51. Lopez LC, Escames G, Ortiz F, Ros E, Acuña-Castroviejo D. Melatonin restores the mitochondrial production of ATP in septic mice. Neuro Endocrinol Lett 2006;27:623-630.

52. Escames G, León J, Macías M, Khaldy H, Acuña-Castroviejo D. Melatonin counteract lipopolysaccharide-induced expression and activity of mitochondrial nitric oxide synthase in rats. FASEB J 2003;17:932-934. https://doi.org/10.1096/fj.02-0692fje

53. Martín M, Macías M, Escames G, León J, Acuña-Castroviejo D. Melatonin but not vitamins C and E maintains glutathione homeostasis in t-butyl hydroperoxide-induced mitochondrial oxidative stress. FASEB J 2000;14:1677-1679. https://doi.org/10.1096/fj.99-0865fje

54. Tan D-X, Manchester LC, Esteban-Zubero E, Zhou Z, Reiter RJ. Melatonin as a potent and inducible endogenous antioxidant: Synthesis and metabolism. Molecules 2015;20:18886-18906. https://doi. org/10.3390/molecules201018886

55. Chen J, Xia H, Zhang L, Zhang H, Wang D, Tao X. Protective effects of melatonin on sepsis-induced liver injury and dysregulation of gluconeogenesis in rats through activating SIRT1/ STAT3 pathway. Biomed Pharmacother 2019;117:109150. https://doi.org/10.1016/j.biopha.2019.109150

56. Zhao L, An R, Yang Y, et al. Melatonin alleviates brain injury in mice subjected to cecal ligation and puncture via attenuating inflammation, apoptosis, and oxidative stress: the role of SIRT1 signaling J Pineal Res 2015;59:230-239. http://doi.org/10.1111/jpi.12254

57. Crespo E, Macias M, Pozo D, et al. Melatonin inhibits expression of the inducible NO synthase in the liver and lung and prevents endotoxaemia in lipopolysaccharide-induced multiple organ dysfunction syndrome in rats. FASEB J 1999;13:1537-1546.

58. Juybari KB, Pourhanifeh MH, Hosseinzadeh A, Hemati K, Mehrzadi S. Melatonin potentials gainst viral infections including COVID-19: Current evidence and new findings. Virus Re 287;2020:198108. https://doi.org/10.1016/j.virusres.2020.198108

59. Huang SH, Cao XJ, Liu W, Shi XY, Wei W. Inhibitory effect of melatonin on lung oxidative stress induced by respiratory syncytial virus infection in mice. J Pineal Res 2010;48(2):109-116. https://doi. org/10.1111/j.1600-079X.2009.00733.x

60. Huang SH, Cao XJ, Wei WJ. Melatonin decreases TLR3-mediated inflammatory factor expression via inhibition of NF-kappa B activation in respiratory syncytial virus-infected RAW264.7 macrophages. J Pineal Res 2008;45(1):93-100. https://doi.org/10.1111/j.1600-079X.2008.00560.x

61. Zhang R, Wang X, Ni L, et al. COVID-19: Melatonin as a potential adjuvant treatment. Life Science 2020;117583;12234-62789. https://doi.org/10.1016/j.lfs.2020.117583

62. Frontline Critical Care Alliance. www.covid19criticalcare.com (accessed 4 February 2021).

63. Anderson G, Reiter RJ. Melatonin: Roles in influenza, Covid-19, and other viral infections. Rev Med Virol 2020;30:e2109. https://doi.org/10.1002/rmv.2109

64. Zisapel N. Melatonin and sleep. Open Neuroendocrinol J 2010;3:85-95. 